\title{
Genetic markers of body composition and carcass quality in grazing Brangus steers
}

\author{
M.C. Baeza ${ }^{1,2}$, P.M. Corva ${ }^{1}$, L.A. Soria ${ }^{3}$, G. Rincon ${ }^{4}$, J.F. Medrano ${ }^{4}$, \\ E. Pavan ${ }^{5}$, E.L. Villarreal ${ }^{5}$, A. Schor ${ }^{6}$, L. Melucci ${ }^{5}$, C. Mezzadra ${ }^{5}$ and \\ M.C. Miquel ${ }^{3}$ \\ ${ }^{1}$ Departamento de Producción Animal, Facultad de Ciencias Agrarias, \\ Unidad Integrada Balcarce, Universidad Nacional de Mar del Plata, \\ Balcarce, Argentina \\ ${ }^{2}$ Agencia Nacional de Promoción Científica y Tecnológica, \\ Buenos Aires, Argentina \\ ${ }^{3}$ Cátedra de Genética, Facultad de Ciencias Veterinarias, \\ Universidad de Buenos Aires, Buenos Aires, Argentina \\ ${ }^{4}$ Department of Animal Science, University of California, Davis, CA, USA \\ ${ }^{5}$ Estación Experimental Agropecuaria INTA Balcarce, Balcarce, Argentina \\ ${ }^{6}$ Facultad de Agronomía, Universidad de Buenos Aires, \\ Buenos Aires, Argentina
}

Corresponding author: P.M. Corva

E-mail: pcorva@balcarce.inta.gov.ar

Genet. Mol. Res. 10 (4): 3146-3156 (2011)

Received January 26, 2011

Accepted July 18, 2011

Published December 19, 2011

DOI http://dx.doi.org/10.4238/2011.December.19.3

\begin{abstract}
The somatotropic axis is a major regulatory pathway of energy metabolism during postnatal growth in mammals. Genes involved in this pathway influence many economically important traits. The association of selected SNPs in these genes with carcass traits was examined in grazing Brangus steers. These traits included final live weight, ultrasound backfat thickness (UBFT), rib-eye area, kidney fat weight, hot carcass weight, and intramuscular fat percentage (\%IMF). Genomic DNA ( $\mathrm{N}=246)$ was genotyped for a panel of 15 tag SNPs located in the growth hormone receptor (GHR), insulin-like growth factor I, insulin-like growth factor-binding protein 6, pro-melanin-
\end{abstract}


concentrating hormone, suppressor of cytokine signaling 2, and signal transducer and activator of transcription 6 (STAT6) genes. Allelic and haplotype frequencies were compared with those of a sample of European breeds ( $\mathrm{N}=177$ steers). Two tag SNPs in the GHR affected \%IMF; one of them (ss86273136) was also strongly associated with UBFT ( $\mathrm{P}<$ $0.003)$. The frequency of the most favorable GHR haplotype for \%IMF was lower in Brangus steers. Moreover, the haplotype carrying two unfavorable alleles was present at a frequency of $31 \%$ in this group. Four tag SNPs on STAT6 had a significant effect on UBFT. One of these, SNP ss115492467, was also associated with \%IMF. The STAT6 haplotype, including all the alleles favoring UBFT, was the most abundant variant (34\%) in the European cattle, while it had a frequency of $14 \%$ in the Brangus steers. The four less favorable variants (absent in the European cattle) were found at a frequency of $38 \%$ in the Brangus steers. These results support the association of GHR and STAT6 SNP with carcass traits in composite breeds, such as Brangus, under grazing conditions.

Key words: Beef cattle; Genetic markers; Growth hormone pathway; Beef quality

\section{INTRODUCTION}

The phenotypic variability in relevant traits for beef production between Bos taurus and Bos indicus has been studied for many years (Wheeler et al., 2001; Thomas et al., 2002; Brunelle et al., 2008). Composite breeds such as Brangus take advantage of this variability, combining the desirable traits for beef production from Angus (B. taurus) with the rusticity and adaptability of Brahman (B. indicus). Brangus has become very popular in the subtropical area of Argentina and in fact is one of the most important beef breeds in the country, together with Angus, Hereford and Braford. Although the Argentine Brangus tends to stabilize in the $3 / 8$ Brahman $-5 / 8$ Angus proportion, there is probably a high variability around these theoretical values when single animals are considered. Because there is no direct control of the genetic contribution from the Zebu breed, unfavorable Zebu alleles could be retained for traits not directly involved in the selection objective, beef quality being a good example of this potential situation.

Advances in molecular technologies have significantly facilitated the genetic dissection of variation in complex traits and have made possible the examination of target genes in key metabolic pathways for associations with economically important traits. In this respect, genes involved in the control of the somatotropic axis, such as growth hormone (GH), growth hormone receptor (GHR) or insulin-like growth factor I (IGFI) are primary candidates for their influence in many traits related to growth rate and body composition (Hale et al., 2000; Thomas et al., 2002; Farber et al., 2006).

Carcass quality is generally measured in terms of carcass yield and content and distribution of fat. This is closely related to the inherent capacity of the animal to regulate energy metabolism and postnatal growth (Zhu et al., 2001; Schenkel et al., 2005). GH and leptin are two important genes involved in the regulation of these factors. Leptin is the central mediator 
in a negative feedback loop regulating energy homeostasis and GH binds to its receptor to stimulate body growth (te Pas et al., 2004; Daix et al., 2008). Numerous association studies involving these genes have been conducted in diverse breeds (Thomas et al., 2007; Garrett et al., 2008; Corva et al., 2009). However, reported evidence is limited for grass-fed cattle. This feeding system results in a reduced growth rate compared to feedlot cattle; however, it has been shown to be highly beneficial in terms of the nutritional value of beef, namely on the composition of the lipid fraction (Nuernberg et al., 2005; Alfaia et al., 2009). A better understanding of the effects of genes regulating growth and adiposity on economically important traits can be of great importance to the beef industry of countries that can efficiently produce grass-fed beef. Therefore, the aim of this study was to evaluate the effect of a panel of selected single nucleotide polymorphism (SNP) from genes of a major growth regulatory pathway, on carcass traits of Brangus produced in a grass-based system.

\section{MATERIAL AND METHODS}

\section{Animals}

Brangus steers were obtained through a collaborative agreement between the intervening research institutions and the Argentine Brangus Association. A total of 246 Brangus steers were produced in two consecutive cycles, 2004/2005 (N = 60) and 2005/2006 (N = 186). Steers from nine different farms (10 to 48 steers each), were grass-fed in two different locations of Buenos Aires Province. Steers from both cycles were progressively slaughtered at a private abattoir as they reached an ultrasound backfat thickness (UBFT) of at least $6 \mathrm{~mm}$ between the 12th and 13th ribs. There were three slaughter groups in the first year and six slaughter groups in the second year.

\section{Phenotypic information}

Final body weight (FW), ultrasound rib-eye area (UREA) and UBFT were recorded before slaughter. Hot carcass weight (HCW) and kidney fat (KF) were recorded at slaughter. A block of steaks (11th to 13th ribs) was removed from the carcass $24 \mathrm{~h}$ after slaughter and kept at $-20^{\circ} \mathrm{C}$. Analytical determinations in meat samples were performed at the Meat Laboratory, College of Agriculture, University of Buenos Aires. Rib-eye area (REA) was measured with the aid of a grid and backfat thickness (BFT) was measured at a point three-fourths of the distance of the length of the rib eye from its bone side. Intramuscular fat (IMF) was extracted according to protocol 920.39 of AOAC (1990) and expressed as g/100 g fresh tissue. The number of records and means for the analyzed traits are summarized in Table 1.

\section{DNA extraction and genotyping}

DNA was extracted using a modified salting out method (Miller et al., 1988). DNA concentration was determined spectrophotometrically at $260 \mathrm{~nm}$ and its quality was evaluated on $0.8 \%$ agarose gel electrophoresis.

Brangus and European (B. taurus) steers were genotyped with an SNP panel developed by Rincon et al. (2009). This SNP panel consisted of two tag SNPs in GHR, two in IGFI, 
one in insulin-like growth factor binding protein 6 (IGFBP6), two in pro-melanin-concentrating hormone $(\mathrm{PMCH})$, two in suppressor of cytokine signaling 2 (SOCS2), and six in signal transducer and activator of transcription 6 (STAT6). SNP designations (Rincon et al., 2009) are summarized in Table 2. Genotyping was performed with the Sequenom MASSARRAY(R) platform at GeneSeek Inc. (Lincoln, NE, USA).

Table 1. Number of records, means and standard deviations for carcass and meat quality traits.

\begin{tabular}{lcrr}
\hline Trait & N & Mean & SD \\
\hline FW $(\mathrm{kg})$ & 246 & 447.80 & 48.40 \\
UBFT $(\mathrm{mm})$ & 243 & 6.53 & 1.55 \\
UREA $\left(\mathrm{cm}^{2}\right)$ & 245 & 58.33 & 8.79 \\
KF $(\mathrm{kg})$ & 246 & 3.14 & 1.22 \\
HCW $(\mathrm{kg})$ & 246 & 248.50 & 29.70 \\
BFT $(\mathrm{mm})$ & 245 & 3.28 & 1.28 \\
REA $\left(\mathrm{cm}^{2}\right)$ & 246 & 67.07 & 8.70 \\
IMF $(\%)$ & 244 & 2.50 & 0.95 \\
\hline
\end{tabular}

$\mathrm{FW}=$ final live weight; UBFT $=$ ultrasound backfat thickness; UREA $=$ ultrasound rib-eye area; KF $=$ kidney fat weight; $\mathrm{HCW}=$ hot carcass weight; $\mathrm{BFT}=$ backfat thickness; REA = rib-eye area; IMF = intramuscular fat percentage.

Table 2. Comparison of allele frequencies and Hardy-Weinberg (HWE) equilibrium test between Brangus and European steers for GHR, IGFI, IGFBP6, PMCH, SOCS2, and STAT6 polymorphic tag SNP.

\begin{tabular}{|c|c|c|c|c|c|c|c|c|c|}
\hline \multirow[t]{2}{*}{ Locus } & \multirow[t]{2}{*}{ SNP ID $^{+}$} & \multicolumn{4}{|c|}{ European steers } & \multicolumn{4}{|c|}{ Brangus steers } \\
\hline & & $\mathrm{N}$ & Minor allele & MAF & HWE & $\mathrm{N}$ & Minor allele & MAF & HWE \\
\hline GHR-SNP1 & rs41639262 & 170 & G & $0.465^{\mathrm{a}}$ & 0.757 & 193 & A & $0.373^{b}$ & $<0.001$ \\
\hline GHR-SNP2 & ss 86273136 & 177 & A & $0.000^{\mathrm{a}}$ & - & 227 & A & $0.308^{\mathrm{b}}$ & 0.650 \\
\hline IGFI-SNP2 & ss 252841002 & 173 & $\mathrm{~T}$ & $0.185^{\mathrm{a}}$ & $<0.001$ & 236 & $\mathrm{~T}$ & $0.042^{\mathrm{b}}$ & 1.000 \\
\hline IGFBP6-SNP1 & ss252841008 & 177 & $\mathrm{~T}$ & $0.000^{\mathrm{a}}$ & - & 239 & $\mathrm{~T}$ & $0.285^{\mathrm{b}}$ & 0.039 \\
\hline PMCH-SNP2 & ss 252841021 & 176 & $\mathrm{~T}$ & $0.344^{\mathrm{a}}$ & 0.244 & 235 & $\mathrm{~T}$ & $0.143^{\mathrm{b}}$ & 0.789 \\
\hline SOCS2-SNP2 & ss 252841026 & 173 & $\mathrm{C}$ & $0.399^{\mathrm{a}}$ & 1.000 & 164 & $\mathrm{C}$ & $0.393^{\mathrm{a}}$ & $<0.001$ \\
\hline STAT6-SNP1 & ss 115492458 & 176 & $\mathrm{C}$ & $0.341^{\mathrm{a}}$ & 0.734 & 243 & $\mathrm{C}$ & $0.144^{\mathrm{b}}$ & 0.018 \\
\hline STAT6-SNP2 & ss115492464 & 177 & $\mathrm{~T}$ & $0.000^{\mathrm{a}}$ & - & 243 & $\mathrm{~T}$ & $0.187^{\mathrm{b}}$ & 1.000 \\
\hline STAT6-SNP3 & ss 115492459 & 177 & $\mathrm{~A}$ & $0.133^{\mathrm{a}}$ & 0.312 & 246 & $\mathrm{~A}$ & $0.132^{\mathrm{a}}$ & 0.267 \\
\hline STAT6-SNP4 & ss 115492461 & 177 & $\mathrm{~A}$ & $0.285^{\mathrm{a}}$ & 0.460 & 245 & $\mathrm{~A}$ & $0.241^{\mathrm{a}}$ & 0.305 \\
\hline STAT6-SNP5 & ss 115492467 & 177 & $\mathrm{~T}$ & $0.000^{\mathrm{a}}$ & - & 244 & $\mathrm{~T}$ & $0.086^{\mathrm{b}}$ & 1.000 \\
\hline STAT6-SNP6 & ss 115492472 & 177 & $\mathrm{C}$ & $0.000^{\mathrm{a}}$ & - & 244 & $\mathrm{C}$ & $0.369^{\mathrm{b}}$ & 0.787 \\
\hline
\end{tabular}

${ }^{+}$dbSNP identification (http://www.ncbi.nlm.nih.gov/SNP/; accessed October 29, 2010). European steers (pool of crosses involving Angus, Hereford and Limousin breeds). MAF = minor allele frequency of genetic groups with different superscript letters $(\mathrm{a}, \mathrm{b})$ are significantly different $(\mathrm{P}<0.05)$.

SNP with a call rate below $80 \%$ were discarded. Missing genotypes were inferred with the fastPHASE software (Scheet and Stephens, 2006) with a threshold probability of at least $90 \%$. Allele and genotype frequencies were estimated with the SAS software (SAS/STAT Inst. Inc., version 9.1, 2002, Cary, NC, USA). Departures from HWE (Hardy-Weinberg equilibrium) were tested by the Fischer exact test and association between markers was evaluated using the Allele procedure of SAS. In order to compare allele frequencies between Brangus and European breeds, a sample of steers from the experimental herd of Instituto Nacional de Tecnología Agropecuaria (INTA) were genotyped with the same marker panel that was used for Brangus steers. This sample consisted of 48 Angus, 18 Hereford, 75 Hereford x Angus, and 36 Limousin x (Hereford-Angus) steers. Maximum likelihood estimates of haplotype frequen- 
cies for GHR and STAT6 genes were generated using an expectation-maximization algorithm. Based on these estimates, the probability of possessing a given haplotype pair was assigned to each individual (Haplotype procedure of SAS/STAT).

\section{Association analysis}

The effects of individual SNP were evaluated with the following linear model:

$$
\mathrm{Y}_{\mathrm{ijk} l}=\mu+\mathrm{M}_{\mathrm{i}}+\mathrm{G}(\mathrm{C})_{\mathrm{j}}+\mathrm{C}_{\mathrm{k}}+\mathrm{e}_{\mathrm{ijk} \mathrm{l}}
$$

where $Y_{i j k l}$ is the $\mathrm{l}^{\text {th }}$ observation of a given trait; $\mu$ is the general mean; $M_{i}$ is the fixed effect of $\mathrm{i}^{\text {th }}$ genotype of the individual SNP $(\mathrm{i}=\mathrm{AA}, \mathrm{AB}, \mathrm{BB}) ; G(C)$ is the fixed effect of $\mathrm{j}^{\text {th }}$ contemporary group nested within the fattening cycle $(\mathrm{j}=1, \ldots, 23) ; C_{k}$ is the fixed effect of $\mathrm{k}^{\text {th }}$ fattening cycle (year), and $e_{i j k l}$ is a random error. A contemporary group was defined as a group of animals raised in the same farm and with the same slaughter date. The effect of sire was confounded within the contemporary group. SNPs with a minor allele frequency of 0.10 or less were not included in the analysis. Initially, two-way interactions between markers and other fixed effects in the model were tested but they were not significant. Therefore, they were excluded from the model. To correct for the effect of multiple testing, the false discovery rate criterion (FDR) was applied. FDR can be defined as the proportion of false-positive results of all significant tests (Benjamini and Hochberg, 1995). This method is regarded as more powerful than the Bonferroni correction. For tightly linked SNP, the Bonferroni correction is too conservative (Balding, 2006). Therefore, the use of FDR criterion would be more appropriate for this situation. Comparison of least square means was performed with the Tukey test. Additive and dominance effects were estimated through linear contrasts. The additive effect was estimated as half the difference between the two homozygote means and the dominance effect was estimated as the deviation of the heterozygote from the mean of the two homozygotes (Falconer and Mackay, 1996). In the absence of one of the homozygous genotypes for some of the markers, additive and dominance effects were not estimated. The general linear model procedure of the SAS/STAT software was used to test these hypotheses.

\section{RESULTS}

A total of 5712 genotypes were obtained (2461 from European and 3251 from Brangus steers). SOCS2-SNP1 was discarded because its call rate was only 46\%. From the other 14 tag SNP, only seven were polymorphic in European steers while 12 SNP were polymorphic in Brangus steers. IGFI-SNP1 and PMCH-SNP1 showed no polymorphisms in any group. Table 2 summarizes the allele frequencies of informative SNP for both genetic groups. There were significant differences $(\mathrm{P}<0.05)$ between the allelic frequencies of European and Brangus steers for all markers except for SOCS2-SNP2, STAT6-SNP3 and STAT6-SNP4. Departures from HWE were found. These deviations were not unexpected due to the strong selection applied in these breeds and their reduced effective population size. IGFI-SNP2 had an allelic frequency of 0.04 and it was discarded from the association analysis. Minor allele frequency of STAT6-SNP5 was below 0.1; however, this SNP was kept in the association analysis because it was polymorphic only in Brangus steers, suggesting a genetic contribution from $B$. indicus (Brahman) to the composite breed. 
Maximum likelihood estimates of haplotype frequencies were obtained for GHR and STAT6 genes from unphased genotypes (Table 3). Haplotypes inferred with a threshold probability below $90 \%$ were discarded. Differences in haplotype frequencies between Brangus and European steers were found for the most abundant haplotypes. Two possible haplotypes were identified for GHR in European steers, and three in Brangus steers. The G-A haplotype of GHR that was absent in European steers, had a frequency of $31 \%$ in Brangus steers. Four possible haplotypes were identified for STAT6 in European steers, and eight in Brangus steers. The four haplotypes that were absent in European steers, represented 38\% of the total in Brangus steers.

Table 3. Estimated haplotype frequencies for polymorphisms in the GHR and STAT6 genes.

\begin{tabular}{llcc}
\hline Gene & Haplotype & \multicolumn{2}{c}{ Frequency } \\
\cline { 3 - 4 } & & European steers & Brangus steers \\
\hline GHR & A-G & $0.54 \pm 0.03$ & $0.38 \pm 0.03$ \\
& G-G & $0.46 \pm 0.03$ & $0.31 \pm 0.02$ \\
G-A & - & $0.31 \pm 0.02$ \\
\hline STAT6 & C-C-C-G-C-T & $0.34 \pm 0.03$ & $0.14 \pm 0.02$ \\
& G-C-C-A-C-T & $0.28 \pm 0.02$ & $0.24 \pm 0.02$ \\
& G-C-C-G-C-T & $0.24 \pm 0.02$ & $0.11 \pm 0.01$ \\
& G-C-A-G-C-T & $0.13 \pm 0.02$ & $0.13 \pm 0.01$ \\
G-T-C-G-C-C & - & $0.19 \pm 0.02$ \\
& G-C-C-G-C-C & - & $0.10 \pm 0.01$ \\
G-C-C-G-T-C & - & $0.08 \pm 0.01$ \\
G-C-C-G-T-T & - & $0.007 \pm 0.004$ \\
\hline
\end{tabular}

European steers $(\mathrm{N}=170$ for GHR and $\mathrm{N}=175$ for STAT6). Brangus steers $(\mathrm{N}=193$ for GHR and $\mathrm{N}=241$ for

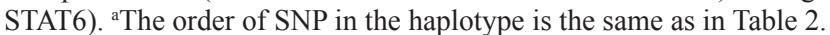

\section{Association analysis}

The effects of fattening cycle (year) and contemporary group were significant $(\mathrm{P}<$ 0.05 ) for all recorded traits, with the exception of REA, which was not affected by the cycle, and \%IMF, which showed no variation among different contemporary groups. Significant associations between recorded traits and the selected tag SNP are shown in Table 4. IGFBP6SNP1, SOCS2-SNP2, STAT6-SNP2, and STAT6-SNP3 showed an effect on carcass traits that became not significant after adjustment for multiple testing. After FDR correction (q-value $<0.10$ ), polymorphisms that showed a significant effect on carcass traits were those located in two of the six genes analyzed, GHR and STAT6. Initially, GHR-SNP2 was found to be associated with UBFT $(\mathrm{P}<0.0003)$, BFT $(\mathrm{P}<0.062)$ and \%IMF $(\mathrm{P}<0.027)$ as well as UREA $(\mathrm{P}<$ $0.058)$. After FDR correction, this polymorphism was strongly associated only with BFT ( $\mathrm{P}<$ 0.003). The heterozygous genotype for this SNP presented the highest value for UBFT (Table 5). In relation to the IMF content, the two SNP on GHR gene had a significant effect. GHRSNP1 was associated with \%IMF and GHR-SNP2 showed a trend to affect the \%IMF (Table 4). The A allele in GHR-SNP1 and the G allele in GHR-SNP2 were the favorable ones for IMF content. Animals with the AA genotype for GHR-SNP1 showed $23.75 \%$ higher \%IMF than those with the GG genotype and animals with the GG genotype for GHR-SNP2 had 27.31\% higher \%IMF than those with the AA genotype (Table 5). The most abundant genotype for GHR-SNP1 in Brangus steers disadvantaged marbling deposition while the most abundant genotype for the other SNP in GHR favored intramuscular fat accretion. To test the interaction between the two GHR polymorphisms, a linear model similar to the previous one was used, but with the inclusion of both markers simultaneously. Neither the main effect of each SNP 
or their interaction, were significant for \%IMF (data not shown). The AG haplotype in GHR, which was the most abundant in both genetic groups, contained the two favorable alleles for \%IMF, but its frequency was 16 points lower in Brangus steers. In addition, the GA haplotype, which carried the two unfavorable alleles for \%IMF, was absent in B. taurus steers while it had a frequency of 0.31 in Brangus steers (Table 3).

Four of the six SNP analyzed in STAT6 showed a significant effect on BFT (Table 4), three of them (STAT6-SNP1, STAT6-SNP5 and STAT6-SNP6) were related to UBFT and one (STAT6-SNP4) was associated with BFT measured post mortem. STAT6-SNP5 was also associated with \%IMF. These results suggest that the C allele of STAT6-SNP5 had a positive effect on the development of both marbling and BFT (Table 5). The STAT6-SNP6 polymorphism, involving a $\mathrm{T} / \mathrm{C}$ substitution, was initially associated with overall body composition of Brangus, showing a significant effect on FW, HCW, KF, UBFT, and REA. After adjusting for multiple tests only a significant additive effect on UBFT remained as significant (Table 4). Previous studies in European feedlot cattle did not report this SNP as significant (Rincon et al., 2009). This polymorphism as well as STAT6-SNP5, was not found in European steers. The C allele of STAT6-SNP6, only found in Brangus steers, had a negative effect on UBFT; therefore, animals with genotype CC showed $0.76 \mathrm{~mm}$ less backfat thickness than animals with genotype TT (Table 5). The minor genotype frequencies of STAT6-SNP1, STAT6-SNP4 and STAT6-SNP5 were below 0.05 , so only two genotype classes were included in the association analysis. The homozygous genotypes, GG in STAT6-SNP4 and CC in STAT6-SNP5, were associated with higher BFT and UBFT, respectively. However, heterozygote animals for STAT6-SNP1 had higher backfat thickness than the homozygous ones $(6.58 v s 6.18 \mathrm{~mm})$. Additive and dominance effects could only be tested for three of the six significant markers. An overdominant effect of GHR-SNP2 was detected for backfat thickness. The remaining SNP had additive effects only.

\begin{tabular}{|c|c|c|c|}
\hline Meat trait & SNP & $P$ value & q-value* \\
\hline IMF (\%) & GHR-SNP1 & 0.0123 & 0.068 \\
\hline$\overline{\mathrm{UBFT}}(\mathrm{mm})$ & GHR-SNP2 & 0.0003 & 0.003 \\
\hline UREA $\left(\mathrm{cm}^{2}\right)$ & & 0.0576 & 0.633 \\
\hline $\mathrm{BFT}(\mathrm{mm})$ & & 0.0618 & 0.340 \\
\hline IMF (\%) & & 0.0268 & 0.098 \\
\hline IMF (\%) & IGFBP6-SNP1 & 0.0947 & 0.260 \\
\hline $\operatorname{REA}\left(\mathrm{cm}^{2}\right)$ & SOCS2-SNP2 & 0.0187 & 0.206 \\
\hline$\overline{\mathrm{UBFT}}(\mathrm{mm})$ & $\begin{array}{l}\text { STAT6-SNP1 } \\
\end{array}$ & 0.0181 & 0.050 \\
\hline $\mathrm{KF}(\mathrm{kg})$ & STAT6-SNP2 & 0.0377 & 0.207 \\
\hline$\underline{\mathrm{HCW}}(\mathrm{kg})$ & & 0.0864 & 0.475 \\
\hline$\underline{\mathrm{KF}}(\mathrm{kg})$ & STAT6-SNP3 & 0.0628 & 0.230 \\
\hline BFT (mm) & STAT6-SNP4 & 0.0006 & 0.006 \\
\hline UBFT (mm) & STAT6-SNP5 & 0.0032 & 0.018 \\
\hline IMF (\%) & & 0.0043 & 0.047 \\
\hline FW (kg) & STAT6-SNP6 & 0.0887 & 0.976 \\
\hline $\operatorname{UBFT}(\mathrm{mm})$ & & 0.0050 & 0.018 \\
\hline $\mathrm{KF}(\mathrm{kg})$ & & 0.0334 & 0.367 \\
\hline $\mathrm{HCW}(\mathrm{kg})$ & & 0.0379 & 0.416 \\
\hline $\operatorname{REA}\left(\mathrm{cm}^{2}\right)$ & & 0.0493 & 0.271 \\
\hline
\end{tabular}

$\mathrm{IMF}=$ intramuscular fat; UBFT $=$ ultrasound backfat thickness; UREA $=$ ultrasound rib-eye area; $\mathrm{BFT}=$ backfat thickeness; REA = rib-eye area; $\mathrm{KF}=$ kidney fat; $\mathrm{HCW}=$ hot carcass weight. *False discovery rate criterion for multiple test correction. Significant results $(\mathrm{q}<0.10)$ are in bold. Only significant associations are shown. 


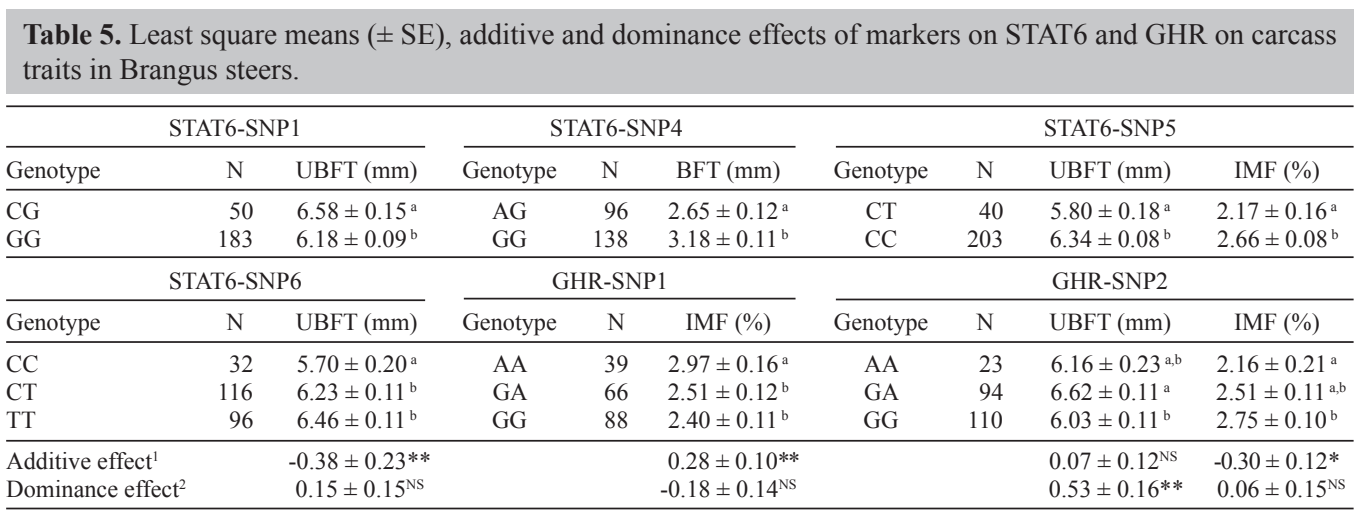

a,bMeans of a given trait and marker with different superscript letters are significantly different (adjusted P value $<0.05$ ). ${ }^{1}$ Additive effect estimated as a half the difference between the most abundant and the less abundant homozygous genotypes. ${ }^{2}$ Dominance effect is estimated as the deviation of the heterozygote from the mean of the two homozygotes. NS $=$ not significant; ${ }^{*} \mathrm{P}<0.05 ; * * \mathrm{P}<0.01$. For abbreviations, see legend to Table 4.

\section{DISCUSSION}

Mammalian metabolism is regulated by the synchronized action of different hormones, with complex feedback and control mechanisms. A mayor regulatory pathway corresponds to the somatotropic axis that plays a key role in regulation of energy metabolism during postnatal growth.

In this study, a total of 423 animals were genotyped for 15 SNP belonging to six genes related to the somatotropic axis. These polymorphisms were identified to be tag SNP in the discovery panel (Rincon et al., 2009).

Growth hormone, one of the most important factors in the somatotropic axis, is responsible for the regulation of diverse biological processes such as muscle and mammary gland development and lipid and carbohydrate metabolism (Akers, 2006). GH exerts its action through its receptor (GHR), which activates GH by binding to it. Many studies have addressed the association of polymorphisms in GH and GHR with carcass merit in several commercial breeds (Hale et al., 2000; Di Stasio et al., 2005; Garret et al., 2008).

In addition, numerous mutations located within GHR have been associated with variation in quantitative traits in dairy cattle. The missense p.Phe279Tyr mutation is one of the most promising markers to improve protein content and milk yield (Sun et al., 2009). Other studies reported the effect of this polymorphism on feed intake, feed conversion, and traits related to energy balance (Banos et al., 2008). Numerous investigations attempting to correlate GHR allelic variants with quantitative traits reveal the multifunctional nature of the GHR gene, encouraging the study of the effects of this gene on economically important traits in beef cattle.

The marked phenotypic variability between $B$. taurus and $B$. indicus includes differences in growth rate. In the present study, markers of the GH pathway showed significant differences in allelic frequencies between European and Brangus steers. Moreover, four SNP on STAT6 and two on GHR showed a significant effect on carcass traits.

The structure of the bovine GHR gene consists of 10 exons and 9 introns. GHR-SNP2 is located on the 5'untraslated region in exon 1 of the GHR gene (Garrett et al., 2008). The pattern of allele frequencies for GHR-SNP2 supports the statement of Garrett et al. (2008) sug- 
gesting that the unfavorable A allele comes from the indicine breed. Although the magnitude of the effect of this SNP on UBFT was similar to that reported by Garrett et al. (2008), here an overdominance effect was also detected, while in the other experiment the effect of the same locus was mostly additive. Overdominance seems to be a common feature of markers of genes involved in the GH axis when crosses of B. taurus with B. indicus are evaluated (Pereira et al., 2005; Thomas et al., 2007). In relation to intramuscular fat, the distribution of frequencies of GHR markers in Brangus showed that the most abundant genotype for one of these SNP (GHR-SNP1) was not favorable for marbling deposition while the most abundant genotype of the other marker (GHR-SNP2), favored fat accretion (Table 5). These results differed from those of Garrett et al. (2008), in which GHR-SNP2 was not associated with \%IMF. This discrepancy could be attributed to the feeding system, given that the pattern of IMF accretion differs between grain- and grass-based diets (Alfaia et al., 2009).

The AG haplotype of the GHR gene contained the two favorable alleles for \%IMF. The frequency of this haplotype in Brangus steers was lower than in European breeds $(0.38$ vs 0.54). Moreover, there were no significant differences between the frequencies of the three possible haplotypes in Brangus steers. These results are consistent with the fact that there has been little selection pressure to increase marbling deposition in commercial Brangus.

Another gene included in this study that showed significant effects on carcass traits was STAT6, which is a member of the STAT family of transcription factors. STAT6 is the principal transcription factor involved in interleukin-4 (IL-4) and IL-13 signaling (Darnell Jr., 1996). Ghilardi et al. (1996) postulated STAT6 as a possible mediator of leptin effects on weight regulation. Recently, the activation of STAT6 through IL-4 was associated with the onset of adipogenesis (Hua et al., 2004).

The STAT6 polymorphisms reported in the present study were described previously by Rincon et al. (2009). STAT6-SNP1, STAT6-SNP2 and STAT6-SNP3 are located in intron 1 of the gene, whereas STAT6-SNP4, STAT6-SNP5 and STAT6-SNP6 are situated in intron 8, exon 10 and intron 20 of STAT6, respectively. It is worth noting that STAT6-SNP1, STAT6SNP3 and STAT6-SNP4 were identified in a panel of European breeds, whereas the others were segregating in indicine breeds only.

Four of the six polymorphisms in STAT6 were significantly associated with backfat thickness. STAT6-SNP6 was the only polymorphism in STAT6 that showed a weak effect on all traits related to body weight and carcass composition. Most of these effects became not significant after correction for multiple tests, but this could be a consequence of the small sample size. Therefore, the relevance of this SNP as a useful marker cannot be ruled out without further evaluation.

The haplotype of STAT6 that included all the alleles favoring backfat thickness (CCCGCT) represented the most abundant variant (34\%) in European steers, while it had a frequency of $14 \%$ in Brangus steers. On the contrary, the four least favorable haplotype variants were absent in European steers while they represented 38\% of the haplotypes present in Brangus steers.

Given the linkage phase of markers on this gene, $53 \%$ of the haplotypes present in Brangus contained only two favorable alleles for UBFT. From these, $29 \%$ correspond to haplotypes that originated in Brahman.

According to the trend in allele and haplotype frequencies reported here, the inclusion of Zebu in a composite breed seems to have some deleterious effects on meat quality traits. It 
would be worth studying if this is just a hitchhiking effect or a correlated response to selection for conformation and growth rate. Current selection in Argentine Brangus is strongly based in phenotypic evaluation and growth expected progeny differences, given that expected progeny differences for REA and UBFT were included in the Sire Summary very recently.

Genomic tools could assist in the design and selection of an optimized composite breed. This is especially important to Argentine Brangus, because the Herdbook of the breed is open, and it is possible to grade up starting from matings of the founder breeds.

The present study evaluated the effect of several genes belonging to a major regulatory pathway of growth on relevant traits of beef production in a typical grazing system. SNP on GHR and STAT6 genes appeared as candidate markers of variation in backfat thickness and intramuscular fat in Brangus steers. These SNP could be integrated to marker panels for the selection of composite breeds, to improve adaptability and growth potential, avoiding detrimental effects on meat quality.

\section{ACKNOWLEDGMENTS}

Research supported by grants from the ANPCyT (\#PICT 2006/669) and UNMdP. This paper is a partial requirement for M.C. Baeza to obtain the degree of PhD in Agricultural Sciences at the UIB's postgraduate program, University of Mar del Plata.

\section{REFERENCES}

Akers RM (2006). Major advances associated with hormone and growth factor regulation of mammary growth and lactation in dairy cows. J. Dairy Sci. 89: 1222-1234.

Alfaia CPM, Alves SP, Martins SIV, Costa ASH, et al. (2009). Effect of the feeding system on intramuscular fatty acids and conjugated linoleic acid isomers of beef cattle, with emphasis on their nutritional value and discriminatory ability. Food Chem. 114: 939-946.

AOAC (1990). Fat (Crude) or Ether Extraction in Animal Feed. Method 920.39 (4.5.01). In: Official Methods of Analysis (Helrich K, ed.). 15th edn. The Association of Official Analytical Chemists, Inc., Virginia.

Balding DJ (2006). A tutorial on statistical methods for population association studies. Nat. Rev. Genet. 7: 781-791.

Banos G, Woolliams JA, Woodward BW, Forbes AB, et al. (2008). Impact of single nucleotide polymorphisms in leptin, leptin receptor, growth hormone receptor, and diacylglycerol acyltransferase (DGAT1) gene loci on milk production, feed, and body energy traits of UK dairy cows. J. Dairy Sci. 91: 3190-3200.

Benjamini Y and Hochberg Y (1995). Controlling the false discovery rate: a practical and powerful approach to multiple testing. J. Roy. Stat. Soc. 57: 289-300.

Brunelle BW, Greenlee JJ, Seabury CM, Brown CE, et al. (2008). Frequencies of polymorphisms associated with BSE resistance differ significantly between Bos taurus, Bos indicus, and composite cattle. BMC Vet. Res. 4: 36.

Corva PM, Fernandez Macedo GV, Soria LA, Papaleo MJ, et al. (2009). Effect of leptin gene polymorphisms on growth, slaughter and meat quality traits of grazing Brangus steers. Genet. Mol. Res. 8: 105-116.

Daix M, Pirotte C, Bister JL, Wergifosse F, et al. (2008). Relationship between leptin content, metabolic hormones and fat deposition in three beef cattle breeds. Vet. J. 177: 273-278.

Darnell JE Jr (1996). Reflections on STAT3, STAT5, and STAT6 as fat STATs. Proc. Natl. Acad. Sci. U. S. A. 93: 62216224.

Di Stasio L, Destefanis G, Brugiapaglia A, Albera A, et al. (2005). Polymorphism of the GHR gene in cattle and relationships with meat production and quality. Anim. Genet. 36: 138-140.

Falconer DS and Mackay TFC (1996). Introduction to Quantitative Genetics. 4th edn. Longman Group Ltd., Essex.

Farber CR, Corva PM and Medrano JF (2006). Genome-wide isolation of growth and obesity QTL using mouse speed congenic strains. BMC Genomics 7: 102.

Garrett AJ, Rincon G, Medrano JF, Elzo MA, et al. (2008). Promoter region of the bovine growth hormone receptor gene: single nucleotide polymorphism discovery in cattle and association with performance in Brangus bulls. J. Anim. Sci. 86: 3315-3323. 
Ghilardi N, Ziegler S, Wiestner A, Stoffel R, et al. (1996). Defective STAT signaling by the leptin receptor in diabetic mice. Proc. Natl. Acad. Sci. U. S. A. 93: 6231-6235.

Hale CS, Herring WO, Shibuya H, Lucy MC, et al. (2000). Decreased growth in angus steers with a short TG-microsatellite allele in the P1 promoter of the growth hormone receptor gene. J. Anim. Sci. 78: 2099-2104.

Hua K, Deng J and Harp JB (2004). Interleukin-4 inhibits platelet-derived growth factor-induced preadipocyte proliferation. Cytokine 25: 61-67.

Miller SA, Dykes DD and Polesky HF (1988). A simple salting out procedure for extracting DNA from human nucleated cells. Nucleic Acids Res. 16: 1215.

Nuernberg K, Dannenberger D, Nuernberg G, Ender K, et al. (2005). Effect of a grass-based and a concentrate feeding system on meat quality characteristics and fatty acid composition of longissimus muscle in different cattle breeds. Livest. Prod. Sci. 94: 137-147.

Pereira AP, Alencar MM, Oliveira HN and Regitano LCA (2005). Association of $G H$ and $I G F-1$ polymorphisms with growth traits in a synthetic beef cattle breed. Genet. Mol. Biol. 28: 230-236.

Rincon G, Farber EA, Farber CR, Nkrumah JD, et al. (2009). Polymorphisms in the STAT6 gene and their association with carcass traits in feedlot cattle. Anim. Genet. 40: 878-882.

Scheet $\mathrm{P}$ and Stephens M (2006). A fast and flexible statistical model for large-scale population genotype data: applications to inferring missing genotypes and haplotypic phase. Am. J. Hum. Genet. 78: 629-644.

Schenkel FS, Miller SP, Ye X, Moore SS, et al. (2005). Association of single nucleotide polymorphisms in the leptin gene with carcass and meat quality traits of beef cattle. J. Anim. Sci. 83: 2009-2020.

Sun D, Jia J, Ma Y, Zhang Y, et al. (2009). Effects of DGAT1 and GHR on milk yield and milk composition in the Chinese dairy population. Anim. Genet. 40: 997-1000.

te Pas MF, Visscher AH and de Greef KH (2004). Molecular genetic and physiologic background of the growth hormoneIGF-I axis in relation to breeding for growth rate and leanness in pigs. Domest. Anim. Endocrinol. 27: 287-301.

Thomas MG, Enns RM, Hallford DM, Keisler DH, et al. (2002). Relationships of metabolic hormones and serum glucose to growth and reproductive development in performance-tested Angus, Brangus, and Brahman bulls. J. Anim. Sci. 80: 757-767.

Thomas MG, Enns RM, Shirley KL, Garcia MD, et al. (2007). Associations of DNA polymorphisms in growth hormone and its transcriptional regulators with growth and carcass traits in two populations of Brangus bulls. Genet. Mol. Res. 6: $222-237$.

Wheeler TL, Cundiff LV, Shackelford SD and Koohmaraie M (2001). Characterization of biological types of cattle (Cycle V): carcass traits and longissimus palatability. J. Anim. Sci. 79: 1209-1222.

Zhu T, Goh EL, Graichen R, Ling L, et al. (2001). Signal transduction via the growth hormone receptor. Cell. Signal. 13: 599-616. 